\title{
Ensuring the stability of the deep pit enclosure and foundation bases in the conditions of reconstruction of the architectural monument in the city of Kazan
}

Ilizar Mirsayapov ${ }^{1 *[0000-0001-8358-4918]}$, Rubis Khasanov ${ }^{1[0000-0002-4109-9399]}$, and Danil Safin ${ }^{1[0000-0003-2871-0808]}$

${ }^{1}$ Kazan State University of Architecture and Engineering, 420043 Kazan, Russia

\begin{abstract}
Technical solutions for the reconstruction of the building of the Shamovskaya Hospital, an architectural monument built in 1907-1910, are highlighted in Kazan. The reconstruction involves the construction of a 4storey underground extension to the building. The implementation of the developed architectural solutions revealed a number of problems associated with ensuring the stability of the foundation when developing a deep pit in the immediate $(0.5 \mathrm{~m})$ proximity to the building. The authors propose technical solutions to strengthen the foundations of the existing building of the Shamovskaya Hospital, as well as the structure of the retaining wall.

Keywords. Deep pit, pit enclosing structure, high-pressure soil cementation, bored injection piles, spacer system, bored piles, deep shear, stability, soil berm.
\end{abstract}

\section{Introduction}

The building of the Shamovskaya Hospital was built in 1907-1910 in Kazan on the money of the merchant Y.F. Shamov and named after him. The building project was developed by the Kazan architect K.C. Oleshkevich together with doctors. The three-storey building, designed in the Art Nouveau style, has become an architectural monument of the city. In the plan, the building is symmetrical «Ш»-shaped, with one-story extension, laid out of red brick. Since 2009, the building of the Shamovskaya Hospital has been closed for reconstruction.

\section{Materials and methods}

The architectural concept of the reconstruction of the building involves the conversion of the building into a five-star hotel, which will house a conference hall, a spa complex, parking, restaurants and shops (Fig. 1). The reconstruction of the building involves the construction of a 4-storey extension to the existing building in the underground version (Fig. 2). At the same time, the previous appearance of the Shamovskaya Hospital will be preserved.

*Corresponding author: mirsayapov1@mail.ru 


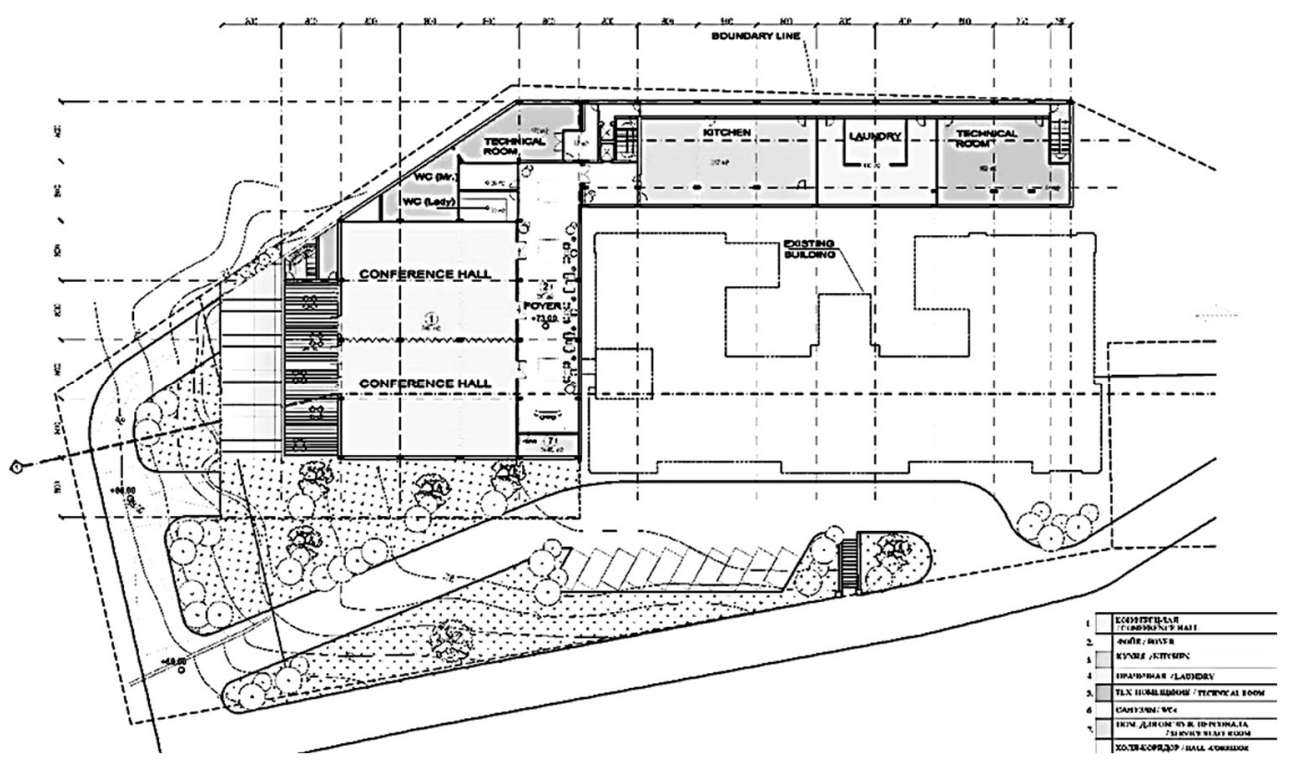

Fig. 1. Schematic plan of the $1^{\text {st }}$ floor of the underground extension to the building of the Shamovskaya Hospital.

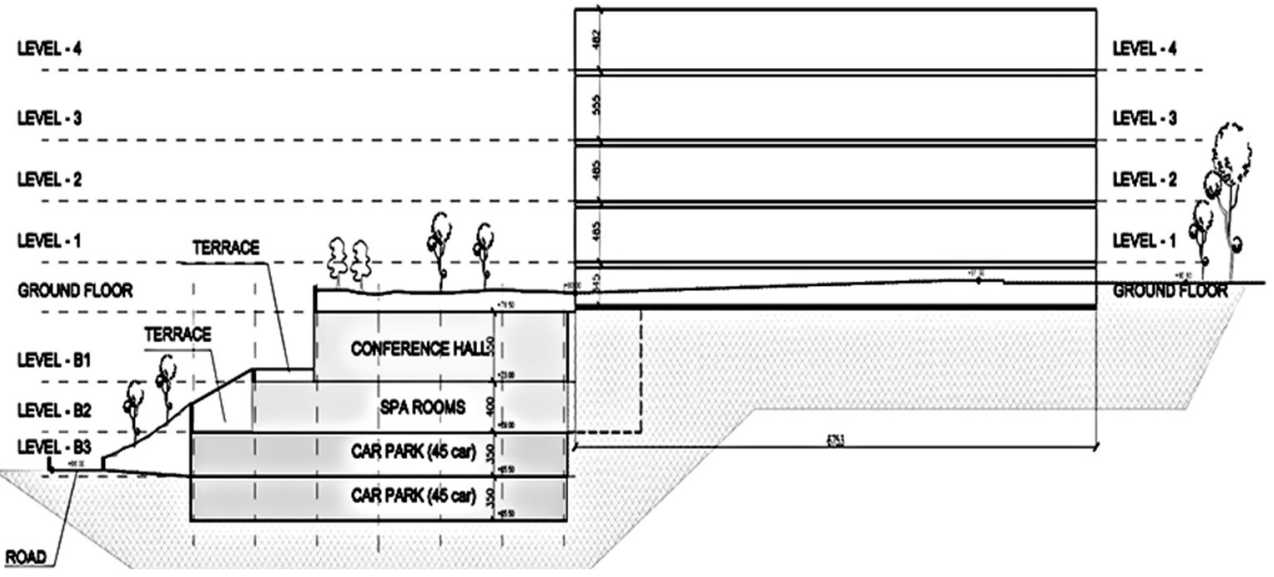

Fig. 2. Schematic section of the building.

Geomorphologically, the territory of the building is located on the alluvial Middle Neopleistocene fourth left-bank terrace of the Volga River valley $\left(d f^{4} Q_{I I}\right)$, complicated in the survey area by erosional landforms. According to the data of exploration wells (Fig. 3).

Quaternary alluvial-deluvial deposits $\left(\mathrm{ad}^{4} \mathrm{Q}_{\mathrm{II}}\right)$, overlain by modern technogenic soils $\left(\mathrm{t}_{\mathrm{IV}}\right)$, take part in the interaction of reconstructed and projected buildings and structures with the geological environment. The maximum thickness of the technogenic layer is $2.2 \mathrm{~m}$. Technogenic soils are distributed from the surface and are mainly represented by a chaotic mixture of loam, sandy loam, sand, soil, construction waste, wood and plant residues. Quaternary alluvial-deluvial loams and sands lie under the bulk soils. Loams are different in the plasticity index (from light to heavy) and consistency index (from hard to soft-plastic), calcareous, ferruginous, with layers and lenses of sand and sandy loam. The sands are mainly small, in the middle part of the section of medium size, polymictic, less often quartz, in areas with layers of loam and sandy loam. Within the study area, the presence of subsident loamy soils (GE-3) with a thickness of 0.6-5.6 $\mathrm{m}$ is noted. Semi-solid and solid loams lying in the 
active zone of soil deformation have uneven subsidence properties when soaked. The initial subsidence pressure ranges from 0.103-0.205 $\mathrm{MPa}$.

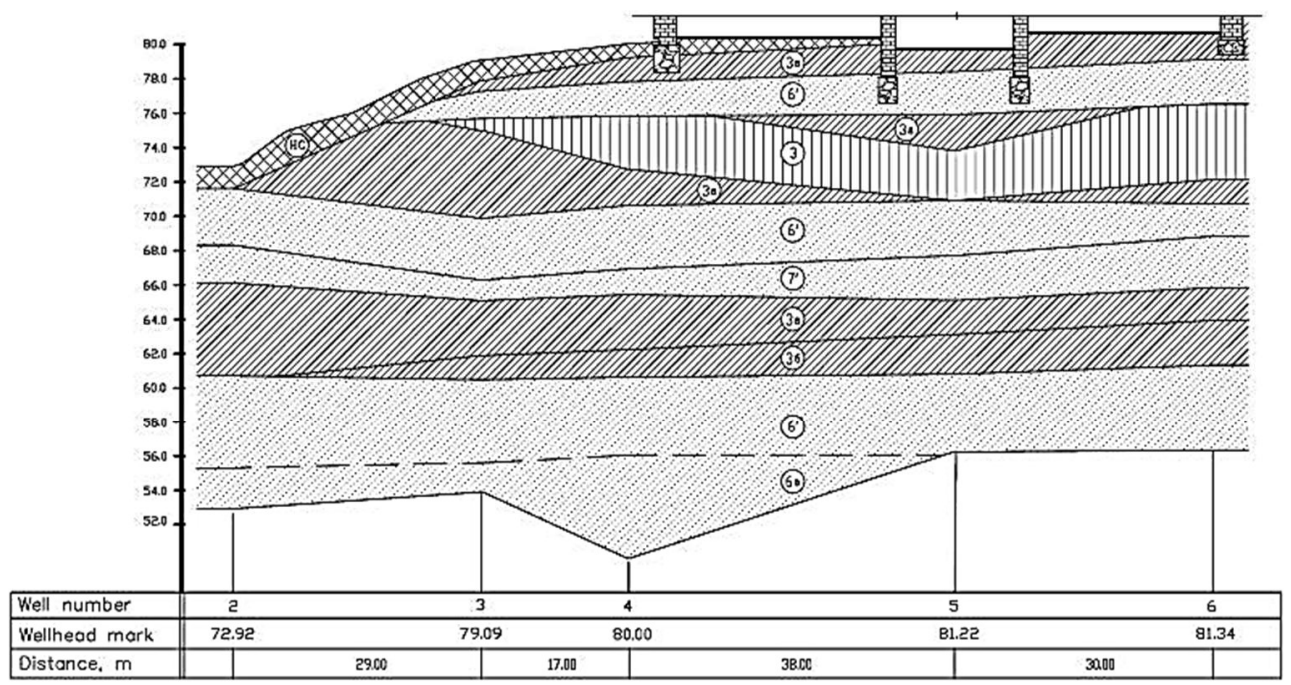

\begin{tabular}{|l|l|}
\hline (3) - semi-solid and solid loom, subsident & (6) - fine, dense, low moisture sand \\
\hline (3i) - semi-solid and solid loom & (6) - fine, dense, water-soturated sand \\
\hline (3i) - hord-plostic loom & () - medium coorse, dense, low moisture sand \\
\hline
\end{tabular}

Fig. 3. Engineering-geological section and strengthening of existing foundations.

When implementing the proposed architectural solutions, a number of problems arise, one of which is that, according to the results of the survey of the technical state of the building structures, the bearing capacity of the basement soils is insufficient to perceive the operational loads that arise after reconstruction. In addition, there are already main cracks in the brick walls, the origin of which is probably also connected with the close location of the edge of the ravine. All this requires strengthening the basement soil of the building, the design of which must also take into account the presence within the compressible thickness of the base layer of subsidence soil (GE-3).

The second, more difficult task is that a 4-storey underground extension to the existing building, designed in a pit with a depth of about $20 \mathrm{~m}$, will be located in the immediate vicinity (at a distance of $0.5 \mathrm{~m}$ ) from the foundation of the end wall of the building along the «1» axis. In this regard, there are questions of preserving the stability of the foundations and the building of the Shamovskaya Hospital itself both during construction and reconstruction, and during its further operation [1-4].

The authors of the article proposed technical solutions for strengthening the bases and foundations of the existing building of the Shamovskaya Hospital, as well as the construction of a retaining wall between the existing building and the newly erected underground extension in a deep pit. The proposed solutions should be considered as a single set of measures designed to ensure the load-bearing capacity and stability of the foundations and the building of the Shamovskaya Hospital as a whole for the duration of reconstruction and further operation, as well as ensuring safe working conditions during the construction of an underground extension [5-8].

Within the framework of the completed working project, the authors solved the following tasks:

- development of a technical solution to strengthen the foundations and foundations of the existing building of the Shamovskaya Hospital;

- development of a design solution for the enclosing structure of the pit; 
- development of measures to ensure the stability of the fence during the development of the soil in the pit and during further operation;

- development of a technological sequence for fencing and excavation in the pit.

Technical solutions for strengthening the foundations of the existing building of the Shamovskaya Hospital allow us to comprehensively solve the following tasks:

1. To transfer a part of the building in the axes «1-4» to a new foundation and thereby minimize the influence of technological processes for the construction of a deep pit in the immediate vicinity of the foundation of the wall along the axis «1» on the technical state of the load-bearing and enclosing structures [9-13].

2. To reduce the movement of the wall in the ground, because the elements of strengthening of the foundations play the role of a gravitational anchor and limit the movement of the upper point of the wall in the ground when excavating the soil from the pit.

3. To reduce the lateral ground pressure of the base of an existing building on the enclosing structure of a deep pit by up to $25 \%$ due to changes in the stress-strain state of the ground within the sliding triangle by transferring part of the forces to the reinforcing elements.

4. To unload the subsidence of the soil thickness of the foundation of the existing building in case of possible soaking of the soil of the entire slope array on which the construction site is located.

In order to optimize the cost of performing work on strengthening the foundations, the existing building was conditionally divided into 2 parts in the plan, where different structural solutions were used to strengthen the foundations.

At the section in the axes «4-14», it was decided to strengthen the bases and foundations by partially transferring the load to vertical drill-injection piles $\varnothing 150 \mathrm{~mm}$ with a length of 9 $\mathrm{m}$. The length of the piles is taken on the basis of the need to fully cut through the layer of subsidence soil of GE-3 and transfer the load to fine-grained dense sands (GE-6'). The piles are joined together by a monolithic reinforced concrete strip grillage with a cross-section of $500 \times 500 \mathrm{~mm}$, and the transfer of loads from the walls of the building to them is carried out by means of through metal rolled beams, concreted in rubble foundations.

On the section of the building in the axes «1-4», it was decided to transfer the existing foundations of the building to a reinforced concrete monolithic foundation plate with a thickness of $500 \mathrm{~mm}$ on a reinforced artificial base. To strengthen the soil, the technology of high-pressure injection of cement mortar into the ground in the design amount through special injectors made of pipes $\varnothing 57 \mathrm{~mm}$, located with a certain step both under the entire newly arranged foundation plate and under the existing rubble foundations, was chosen. Nonremovable injection pipes, adopted in lengths of $9 \mathrm{~m}$ and $12 \mathrm{~m}$, work as reinforcing elements. This method of strengthening the soil allows you to create a rigid-reinforced array in the ground, which has a low compressibility, because the cement mortar after hardening becomes almost incompressible, and the soil around the injector during the injection of the solution under high pressure is also compacted. In addition, the presence of reinforcing elements in the ground will help to reduce the lateral pressure of the soil of the foundations of the existing building on the enclosing structure of the pit.

As the main load-bearing elements of the enclosing structure of the pit, bored piles of $\varnothing 1000 \mathrm{~mm}$ and a length of about $33 \mathrm{~m}$ were adopted, united at the top by a belt grillage, which is connected through reinforcement rods to the foundation plate of the reinforcement of the existing building. In this case, when calculating the enclosing structure for the lateral ground pressure, the top of the wall can be considered fixed at the level of the reinforcement foundation slab.

As noted, the depth of the pit reaches $20 \mathrm{~m}$, which dictates the need for a multi-tiered fastening of the retaining wall in height. At this stage, out of the two considered methods of fastening (spacer, anchor), the spacer fastening was chosen as the most reliable and controllable quality of work.

Due to the fact that the pit does not have an opposite wall, there was no possibility of transferring the spacer force to it, so it was decided to use the monolithic reinforced concrete frame 
of the new building partially erected in the pit as a support structure. To ensure the stability of the enclosing structure until the installation of the spacer system, it is assumed to use the passive pressure of the loading ground berm along the wall along the axis «1» (Fig. 4) [14].

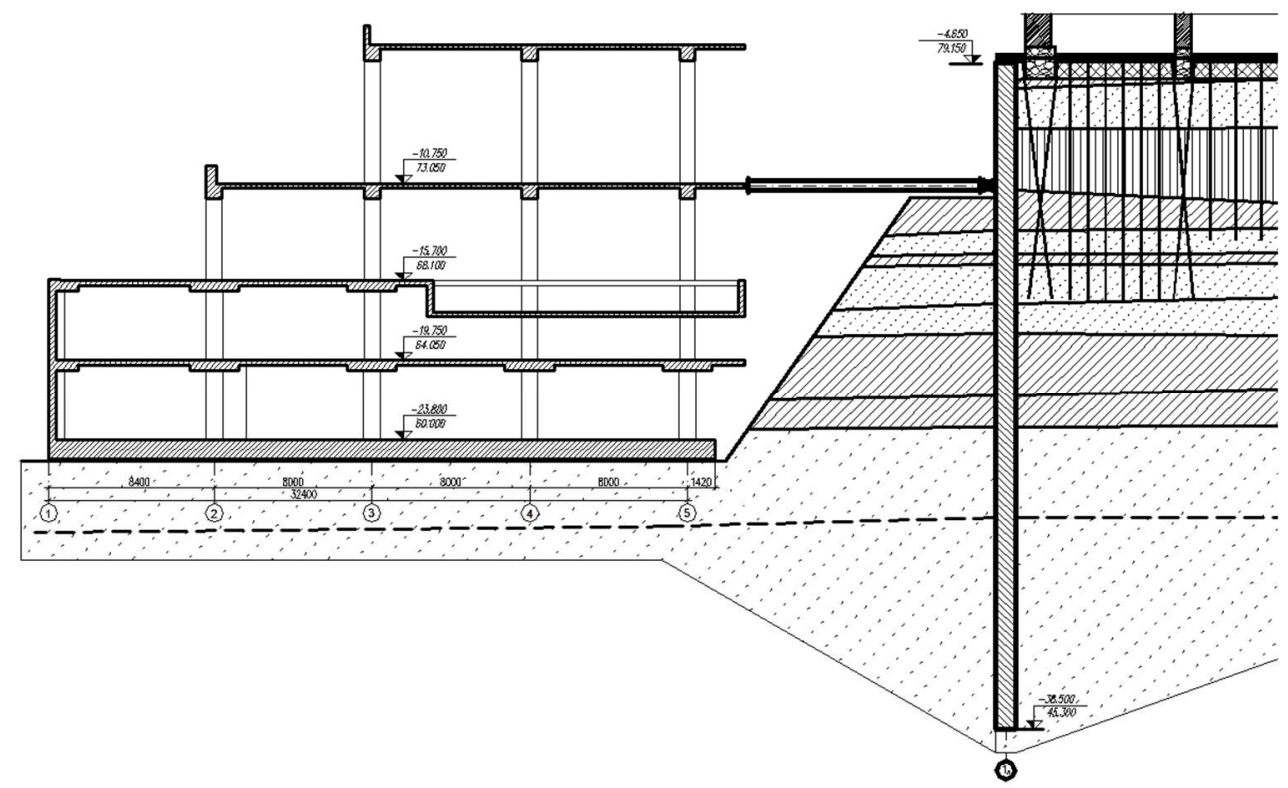

Fig. 4. Installation of the first tier of the spacer system with support on a monolithic frame, section of a soil berm.

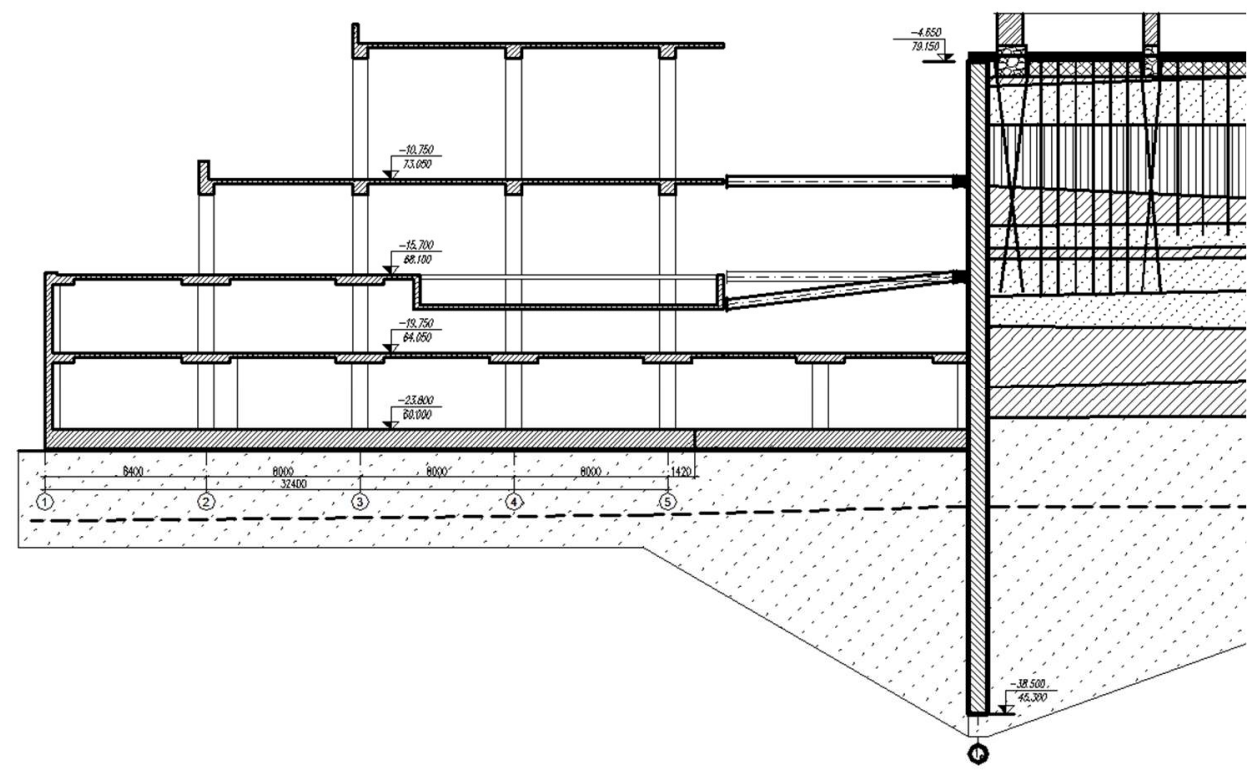

Fig. 5. Dismantling the spacer system and concreting the rest of the monolithic frame.

Thus, in order to ensure the possibility of safe construction of an underground extension to the building of the Shamovskaya Hospital, the following technological sequence of work was proposed:

- installation of a pit fence made of bored piles $\varnothing 1000 \mathrm{~mm}$ and a unifying grillage along the top of the piles with the provision of anchoring with a slab foundation to strengthen the building; 
- excavation of the slope soil up to the level of the base of the foundation of the newly constructed building up to the level of -24.900 with the leaving of the ground berm along the wall in the ground (Fig. 4);

- partial (within 4 spans) construction of a monolithic reinforced concrete frame of an underground extension;

- tiered excavation of berm soil in the pit and installation of a spacer system for fastening the enclosing wall with the transfer of force from the spacers to the frame floors at -10.750 , $-15.700,-19.750$;

- installation of slab foundations of the monolithic frame of the underground extension;

- tiered dismantling of the spacer system with parallel concreting of floor slabs (Fig. 5).

The calculation of the pit fence made of bored piles was performed in the «Lira 9.4» software package for phased (in 4 stages) excavation of soil in the pit.

Based on the experience of designing such structures [15-20], the depth of the wall embedding below the bottom of the pit was previously assumed to be $13 \mathrm{~m}$, while the total height of the projected pit fence was $33 \mathrm{~m}$.

To perform the calculation of the enclosing structure, plots of active and additional pressure on the pit fence were constructed, determined by the formulas:

$$
\begin{gathered}
\sigma_{a}=\gamma \cdot z \cdot \lambda_{a}-\frac{c}{\operatorname{tg} \varphi}\left[1-\lambda_{a}\right] ; \\
\sigma_{q}=q \cdot \lambda_{\alpha},
\end{gathered}
$$

where $\lambda_{\alpha}$ is the coefficient of active soil pressure, determined by the formula:

$$
\lambda_{a}=\left[\frac{\cos \varphi}{1+\sqrt{\frac{\sin (\varphi+\delta) \sin \varphi}{\cos \delta}}}\right]^{2},
$$

here $\varphi$ is the angle of internal friction of the soil, $\delta$ is the angle of friction of the soil at the contact with the wall.

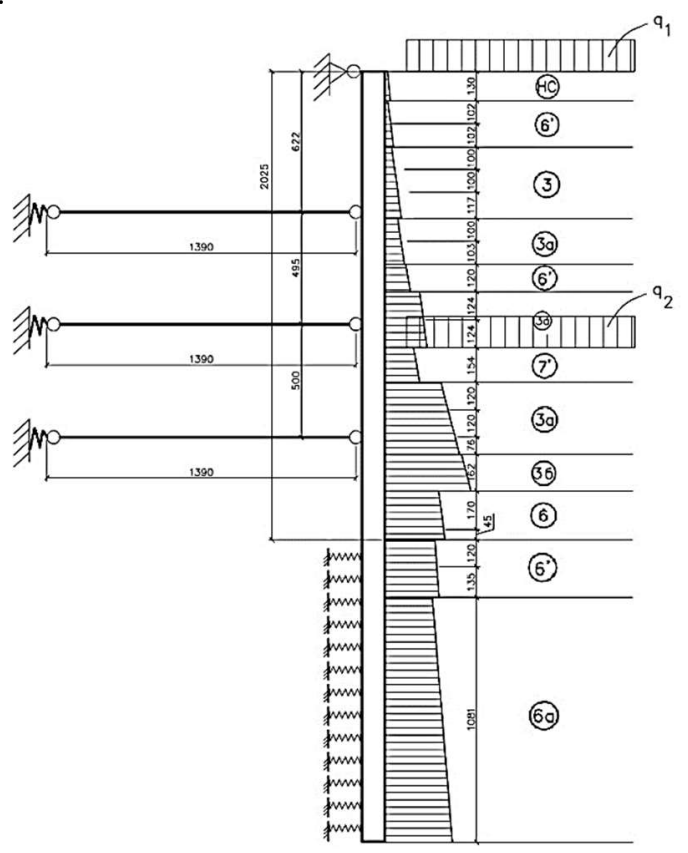

Fig. 6. Design scheme of the enclosing structure at the $4^{\text {th }}$ stage of soil excavation. 
The additional ground pressure transmitted from the foundations of the existing building located in the immediate vicinity is assumed to be a continuous evenly distributed load at a depth of $12 \mathrm{~m}$ (at the level of the bottom of the reinforcement piles of the existing building) with an intensity of $q=108 \mathrm{kPa}$ (Fig. 6).

At each stage of soil excavation, the lower part of the pit fence, located below the intermediate bottom of the pit, was modeled as a beam on an elastic base, using the appropriate bedding values depending on the type of soil and the depth of the layer location. Spacers made of steel pipes transmit force to a monolithic frame of finite rigidity, so in the design scheme, the supports are assumed to be pliable, the characteristics of which are taken based on the pliability of the reinforced concrete frame to the horizontal load (Fig. 7).

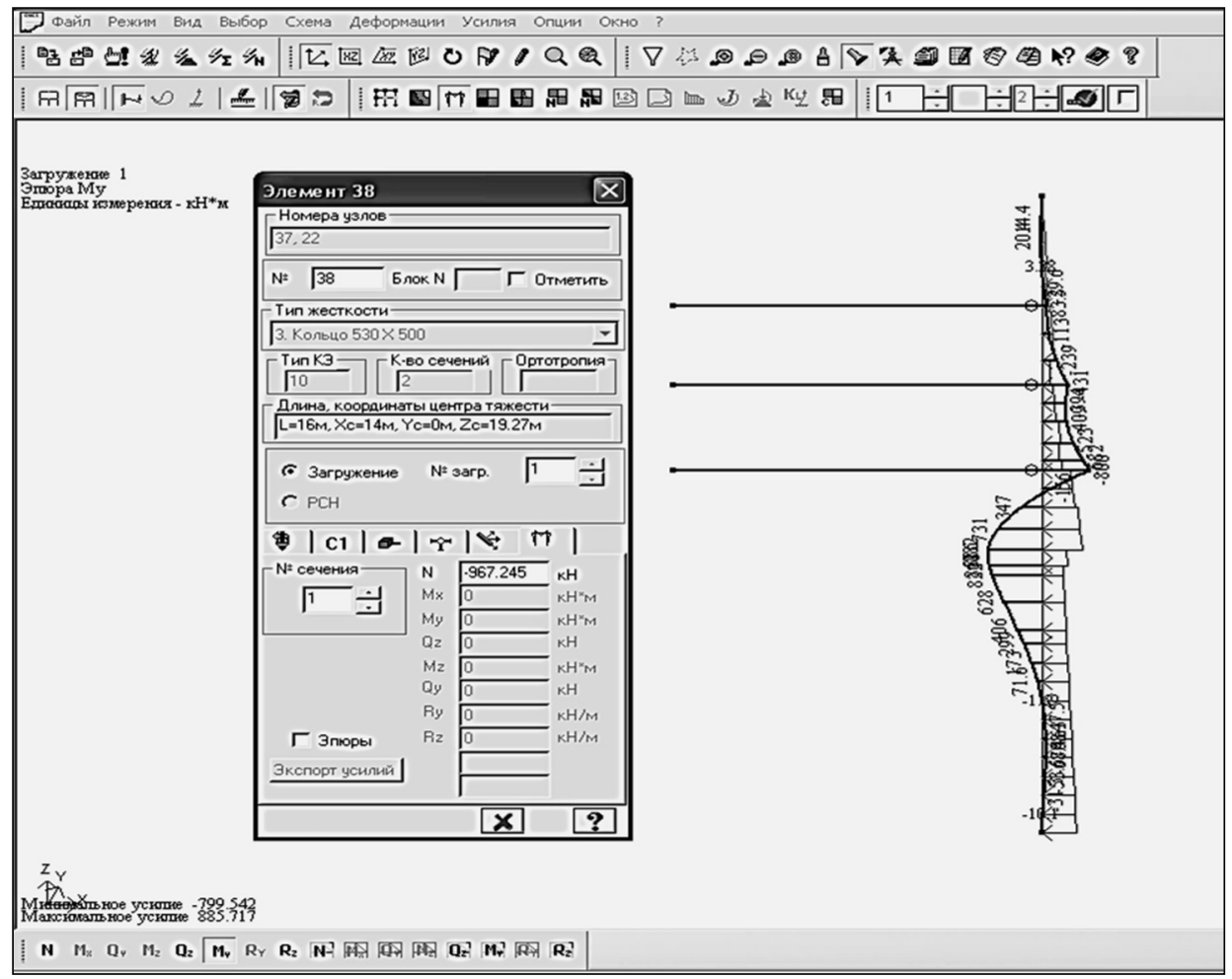

Fig. 7. Plot of bending moments in the building envelope at the $4^{\text {th }}$ stage of soil excavation.

\section{Results}

As a result of calculations, plots of internal forces in the sections of the enclosing structures of the pit were obtained, the forces in the spacers at all stages of soil excavation were determined.

As the calculations showed, the qualitative and quantitative picture of bending moments and forces in the spacers changes at each stage. So, as the ground is excavated, the forces in the upper spacers are reduced from 3 to 8 times. Moreover, the greatest concentration of effort is always observed in the lowest tier for any stage of soil excavation.

Bending moments, in turn, when installing the next tier of spacers, change their sign, stretched and compressed zones of concrete are on one side, then on the other side of the enclosing structure of the pit. However, the absolute values of the bending moments do not change dramatically, the maximum values of the moments at each stage differ within 1.5-2 times. 
The required reinforcement of the enclosing structure made of bored piles and the cross sections of the spacers made of steel pipes are selected according to the maximum values of internal forces.

\section{Discussions}

As you know, round sections in bending conditions work inefficiently, because with a uniform arrangement of the reinforcement along the perimeter of the section, the rods located near the neutral line practically do not participate in the perception of the bending moment. Therefore, for the calculated value of the maximum bending moment per 1 linear meter of the fence for the 4th stage of soil excavation $M_{\max }=885.7 \mathrm{kN} \cdot \mathrm{m}$, it was necessary to install 20 rods $ø 28 \mathrm{~mm}$ of A400 class reinforcement.

The spacers are designed in 3 tiers with a step of the two upper tiers of $3 \mathrm{~m}$, for the lower tier of $2 \mathrm{~m}$ with a steel pipe diameter of $530 \mathrm{~mm}$. In the places where the spacer force is transmitted to the floor slabs along the line of the technological seam of concreting the slabs, it is provided to install embedded elements in the form of two steel plates connected by a rolling channel No. 22 for the convenience of fixing the spacers and excluding the crumpling of the concrete of the floor slabs from the concentrated spacer force.

The maximum displacement of the wall from the deflection of the fence, compression of the spacers and deformation of the monolithic frame and the ground in the embedding zone according to the results of calculations was $19 \mathrm{~mm}$, which does not exceed the permissible value.

The sufficiency of the previously accepted embedding of the enclosing structure below the bottom of the pit was checked by calculating the stability of the ground mass loaded with the weight of the building for a deep slip, for which the method of round-cylindrical sliding surfaces was used. The stability coefficient of the soil mass was 1.9 with a minimum permissible value of 1.3 .

\section{Conclusion}

1. The technological sequence of work has been developed in order to ensure the possibility of safe construction of an underground extension to an existing building [21,22].

2. Calculations of the load-bearing capacity and stability of the enclosing structure of the pit at all stages of soil excavation were performed. The values of the movement of the pit fence, the required reinforcement, and the design of the reinforcement frame of bored piles were established.

3. A ground mass bounded by a wall of bored piles and loaded by a nearby existing building was checked for loss of stability on a round-cylindrical sliding surface.

4. In order to monitor the behavior of a newly constructed and existing building, to detect defects in a timely manner, to prevent and eliminate existing deviations, as well as to assess the correctness of the accepted calculation methods and design decisions, it is necessary to establish geotechnical monitoring of the condition of the buildings under construction and existing.

\section{References}

1. D. Wei, D. Xu, Y. Zhang. A fuzzy evidential reasoning-based approach for risk assessment of deep foundation pit, Tunnelling and Underground Space Technology 97, 103232 (2020). DOI: 10.1016/j.tust.2019.103232.

2. R.A. Mangushev, A.I. Osokin, L.V. Garnyk. Experience in preserving adjacent buildings during excavation of large foundation pits under conditions of dense development Soil, Mechanics and Foundation Engineering 53 5, 291-297 (2016). 
3. Y. Zhou, W-N. Ye, S. Gao. Deformation characteristics of excavation of deep foundation pit at a metro station in Lanzhou Yantu Gongcheng Xuebao, Chinese Journal of Geotechnical Engineering 40, 141-146 (2018). DOI: 10.11779/CJGE2018S1023.

4. J. Lv, Z. Li, X. Xie, B. Fu, H. Fu, H. Zhao, X. Li, Z.Y. Li. Segment stress characteristics and ground deformation caused by constructing closely spaced parallel tunnels under a complex geological condition, Advances in Civil Engineering, 1725210 (2020). DOI: $10.1155 / 2020 / 1725210$.

5. Z. Luo, Y. Li, S. Zhou, H. Di. Effects of vertical spatial variability on supported excavations in sands considering multiple geotechnical and structural failure modes, Computers and Geotechnics 95, 16-29 (2018). DOI: 10.1016/j.compgeo.2017.11.017.

6. S. Ye, Z. Zhao, D. Wang. Deformation analysis and safety assessment of existing metro tunnels affected by excavation of a foundation pit, Underground Space (China), (2020). DOI: $10.1016 /$ j.undsp.2020.06.002.

7. V.V. Konyushkov, A.Zh. Zhussupbekov, V.V. Lushnikov, A.V. Popova. Construction of a multi-level underground structure in condition of modern urban development, Bulletin of Civil engineers 77, 166-174 (2019).

8. D.A. Sapin. Settlements of foundations of adjacent buildings when arranging the trench «slurry wall», Housing construction 4, 8-13 (2015).

9. C.A. Anagnostopoulos, T. Chrysanidis, M. Anagnostopoulou. Experimental data of cement grouting in coarse soils with different superplasticisers, Data in Brief 30, 105612 (2020). DOI: 10.1016/j.dib.2020.105612.

10. Y. Ishihara, S. Haigh, J. Koseki. Assessment of base capacity of open-ended tubular piles installed by the Rotary Cutting Press-in method, Soils and Foundations 60 (5), 1189-1201 (2020). DOI: 10.1016/j.sandf.2020.07.006.

11. W. Wang, Z. Han, J. Deng, X. Zhang, Y. Zhang. Study on soil reinforcement param in deep foundation pit of marshland metro station, Heliyon 5 Iss. 11, e02836 (2019). DOI: 10.1016/j.heliyon.2019.e02836.

12. J. Zhou, X. Gong, R. Zhang. Model tests comparing the behavior of pre-bored grouted planted piles and a wished-in-place concrete pile in dense sand, Soils and Foundations, 59 (1), 84-96 (2019). DOI: 10.1016/j.sandf.2018.09.003.

13. D.R. Safin. Experimental studies of a weak clay base reinforced with sand piles, IOP Conf. Series: Materials Science and Engineering 962, 032020 (2020). DOI: 10.1088/1757-899X/962/3/032020.

14. A. Rismanchian, D.J. White, M.F. Randolph, C.M. Martin. Shear strength of soil berm during lateral buckling of subsea pipelines. Applied Ocean Research 90, 101864 (2019). DOI: $10.1016 /$ j.apor.2019.101864.

15. A.T.C. Goh, F. Zhang, W. Zhang, Y. Zhang, H. Liu. A simple estimation model for 3D braced excavation wall deflection, Computers and Geotechnics 83, 106-113 (2017). DOI: 10.1016/j.compgeo.2016.10.022.

16. A. Nikonorov, V. Terleev, S. Pavlov, I. Togo, Y. Volkova, T. Makarova, V. Garmanov, D. Shishov, W. Mirschel. Applying the Model of Soil Hydrophysical Properties for Arrangements of Temporary Enclosing Structures. Procedia Engineering 165, 1741-1747 (2016). DOI: 10.1016/j.proeng.2016.11.917.

17. C.-F. Zeng, X.-L. Xue, M.-K. Li. Use of cross wall to restrict enclosure movement during dewatering inside a metro pit before soil excavation, Tunnelling and Underground Space Technology 112, 103909 (2021). DOI: 10.1016/j.tust.2021.103909.

18. V.V. Konyushkov, N.Yu. Urazaeva, V.M. Kirillov, L.N. Kondrat'eva. To the issue of studying the diaphragm wall as an enclosing and load-bearing construction of buildings and structures, Bulletin of Civil engineers 66, 68-74 (2018).

19. A. Nikonorov, S. Pavlov, V. Terleev, N. Arefiev, V. Badenko, Y. Volkova. Use of enclosing and temporary special structures under the reconstruction of hydraulic 
facilities in Saint-Petersburg, Procedia Engineering 117, 258-263 (2015). DOI: 10.1016/j.proeng.2015.08.160.

20. W. Xu, D. Tang, R. Tan, Q. Zhang. Application of digital foundation pit system in a deep excavation, Yanshilixue Yu Gongcheng Xuebao, Chinese Journal of Rock Mechanics and Engineering 34, 3510-3517 (2015). DOI: 10.13722/j.cnki.jrme.2014.0246.

21. I.T. Mirsayapov, R.R. Khasanov, D.R. Safin. Design fence of deep foundation pit of the residential complex in a congested urban area, Izvestiya KGASU 32, 183-191 (2015).

22. I.T. Mirsayapov, R.R. Khasanov. Experimental studies of stress-strain state of flexible barriering design with bracing in the process of the phased excavation of the soil, Izvestiya KGASU 16, 129-135 (2011). 